\title{
Management of malignant glioma: role of surgery in relation to multimodality therapy
}

\author{
Perry Black \\ Department of Neurosurgery, Allegheny University of the Health Sciences, MCP $\diamond$ Hahnemann School of Medicine, \\ Philadelphia, PA, USA
}

\begin{abstract}
The goals of surgery for malignant glioma are to establish a histological diagnosis and to achieve mechanical cytoreduction to reduce intracranial pressure (ICP) and possibly alter tumor kinetics. There is controversy concerning the question whether the glioma is a focal or diffuse process; it appears that there may be variability between the two extremes in individual cases. The question of the value of surgery has also been controversial. Review of the literature suggests that both early and long-term postoperative outcome after radical surgical resection are better than the results of either partial resection or simple biopsy, in terms of neurological status and duration of survival. Similarly, reoperation for recurrence of glioma offers reasonable extension of quality survival. Despite the desirability of extensive cytoreductive surgery for malignant gliomas, the presence of viable infiltrative cells beyond the margins of the resection necessitate that surgery be a part of an aggressive multimodality therapeutic approach. Adjunctive measures to control the infiltrative component include newer forms of radiotherapy (such as stereotaxic radiosurgery) and newer delivery techniques for chemotherapy (agents impregnated in biodegradable polymers implanted in the tumor bed after surgical resection), and possibly immunotherapy and gene therapy as they may become feasible in the future. The strategy for management of malignant glioma thus consists of a combination of extensive surgical resection to reduce the accessible tumor burden, followed in rapid sequence by measures to control the infiltrative portion of the tumor. It is recommended that these measures be offered 'up front' rather than delaying treatment until there is clinical or radiographic evidence of tumor recurrence.
\end{abstract}

Keywords: malignant glioma; brain tumor; surgical resection; multimodality therapy

\section{Introduction}

In the past few decades, the advent of microneurosurgical technique, associated with improvements in neuro-anesthesia and perioperative care, has resulted in remarkable advances in the management of benign tumors of the brain - meningiomas, acoustic neurinomas and pituitary tumors. Malignant tumors, however, continue to evade satisfactory clinical control. The extraordinary devel-opment of noninvasive imaging techniques - computerized tomography (CT), magnetic resonance imaging (MRI), positron emission tomography (PET), and single photon emission computed tomography (SPECT) with clear delineation of the neoplastic tissue, have contributed to renewed interest in addressing the immense therapeutic challenge of the malignant glioma. This paper focuses on the role of surgery and its relationship to multimodality therapy for

Correspondence: P Black

Received 15 October 1997; accepted 25 November 1997 anaplastic astrocytoma and glioblastoma multiforme, the most aggressive of the astrocytic neoplasms.

\section{Goals of surgical resection}

The goals of surgery for malignant glioma, as postulated by Shapiro (1982), are as follows:

(1) The establishment of a histological diagnosis.

(2) Tumor cytoreduction for:

(a) Improvement in neurological status by reduction of increased intracranial pressure, and

(b) Possible change in tumor kinetics.

Establishment of histological diagnosis (biopsy) CT scanning is generally accurate in identifying malignant glioma and resolution is even greater 
with MRI (Choksey et al, 1989; Rajan et al, 1994). Although these imaging modalities result in only occasional misdiagnosis, the importance of precise histological diagnosis in planning treatment and in estimating prognosis is of such great value that biopsy, when feasible, is desirable. A biopsy can be obtained by open craniotomy or by stereotaxic technique (Figure 1) via a small trephine. In addition, tissue may be submitted for cell culture for chemosensitivity assay to aid in the selection of appropriate chemotherapy (Darling et al, 1997). An advantage of the open craniotomy technique is that it permits adequate sampling of multiple regions of the lesion to minimize the risk of error in underestimating the degree of malignancy.

\section{Cytoreduction}

On average, malignant gliomas are approximately $5 \mathrm{~cm}$ in diameter, weigh 80 to $100 \mathrm{gm}$, and contain $10^{11}$ cells (Salcman, 1990). This mass, along with surrounding edema, accounts for an estimated 10\% of the intracranial volume. The benefit of cytoreduction is related to:

(a) Reduction of elevated intracranial pressure (ICP). Resection of the tumor mass affords immediate control of the elevated ICP or local tissue compression and may thereby improve neurological function. The mechanical cytoreduction of the mass also buys time for other therapeutic interventions - radiation therapy, chemotherapy, immunotherapy or gene therapy - to be administered and take effect. The

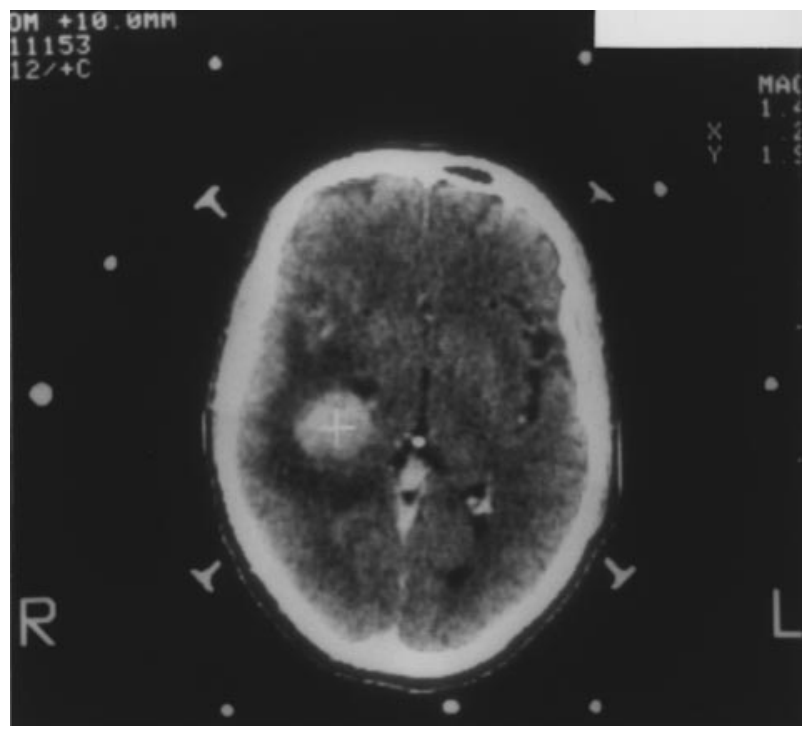

Figure 1 Axial CT scan of a female patient age 45 with a deep right parietal lesion, in preparation for stereotaxic biopsy. The white dots on the periphery are used to compute the stereotaxic coordinates for a probe to stereotaxically target the cursor (cross) electronically imprinted on the scan in the center of the lesion. reduced tumor burden has been shown to have a beneficial effect on cerebral blood flow and metabolism even at sites in the brain distant from tumor resection (Beaney et al, 1985). It has been suggested that these physiological changes may be associated with the functional improvement observed clinically after tumor removal (Salcman, 1990).

(b) Possible change in tumor kinetics. The bulk of the main tumor mass contains hypoxic, poorly vascularized, non-dividing cells which are relatively resistant to radiation and chemotherapy (Salcman, 1982). Radical tumor resection is intended to extend to the outer border of the central tumor mass corresponding to the contrast enhancing rim on the CT or MRI scan. A peritumoral zone of edema contains microscopic tumor cells which are thought to be actively cycling and are the source of continued tumor growth. Reduction of the tumor burden by excision of the main tumor mass potentiates the effect of radiation or chemotherapy directed to the more susceptible actively cycling tumor cells on the periphery of the tumor mass. It has also been suggested that excision of the main tumor mass can induce residual non-dividing cells on the periphery to enter the pool of actively cycling cells which may render them more sensitive to radiation and to chemotherapy (Hoshino, 1984).

\section{Malignant glioma: focal versus diffuse}

The question whether malignant glioma represents a focal or diffuse process is fundamental to the issue of efficacy of focal surgical resection or other treatment modalities. Burger (1987) and Halperin et al (1988) cite numerous instances of neoplastic cells far distant from the main tumor. Kelly et al (1987) have similarly reported, using sequential stereotaxic biopsies, tumor infiltration well beyond the border of the MRI-contrast enhancing margin of the lesion.

In contrast to the view that the malignant glioma is a diffuse, infiltrative process, a number of authors contend that the process is focal in nature (Dyck et al, 1983; Gutin and Leibel, 1985; Hochberg and Pruitt, 1980). The debate has accelerated since the introduction of CT and MR imaging. For example, Hochberg and Pruitt (1980) have shown that 90\% of glioblastoma recurrences in their series were within $2 \mathrm{~cm}$ of the contrast enhancing tumor border.

Judging from the wide disparity in the evidence supporting the respective two extremes in this controversy, we may consider the possibility that there is variability in the degree to which a given case of glioma may be diffuse or focal. Local or distant spread appears to occur. Therapeutically, in patients manifesting either a diffuse or a focal neoplasm, the presence of tumor cells beyond the 
margins of the main tumor mass points to the necessity of a multimodality approach in an effort to control the variable infiltrative component of the neoplastic process.

\section{Surgical resection and outcome}

\section{Perioperative morbidity and mortality}

With advances in neuro-anesthesia, and with the introduction of corticosteroids in the 1960s, operative morbidity and mortality have declined to reasonable levels. In the past decade, the 30-day operative mortality has ranged, in most series, from $0 \%$ (Ciric et al, 1987) to 3.5\% (Fadul et al, 1988; Salcman, 1996); mortality in one series, however, was $17 \%$ (Hollerhage et al, 1991). In these same series, surgical morbidity, including increased neurological deficit, ranged from $8-16 \%$.

A number of authors have observed that partial tumor resection is associated with greater risk of postoperative neurological worsening than either radical excision or stereotaxic biopsy (Ciric et al, 1987; Jelsma and Bucy, 1967; Salcman, 1996). In the series of Ciric et al (1987), 97\% of patients with gross total or nearly gross total resection had improved or stable postoperative neurological status; in contrast, postoperative neurological worsening occurred in $40 \%$ of patients with partial resection. In two other series (Fadul et al, 1988; Vecht et al, 1990) no significant difference was found in the incidence of neurological worsening following gross total resection compared with limited resection. These data from various studies suggest that radical tumor resection is associated with no greater or perhaps less risk of neurological compromise than with partial resection.

Does surgical resection prolong survival?

Conventional therapy for malignant glioma has generally consisted of surgery (variable extent of resection according to the philosophy and experience of the individual neurosurgeon), followed by radiotherapy. Median duration of survival after surgery and radiation in various series has been reported to be 24 months for anaplastic astrocytoma and 9 months for glioblastoma (Walker et al, 1978, 1980; Kristiansen et al, 1981; Chang et al, 1983; Green et al, 1983). Addition of chemotherapy has increased median survival to approximately 11 months for glioblastoma (Walker et al, 1978, 1980; Chang et al, 1983; Green et al, 1983).

Debate continues in the literature concerning the question of whether surgical excision of a malignant glioma is of any benefit in prolonging survival. A number of authors argue that removal of tumor is of no benefit. Table 1 lists these authors and the number of cases of malignant glioma on which they base their conclusions. In the study by Kreth et al (1993), a retrospective comparison was made of 58 glioblastoma patients who had stereotaxic biopsy followed by radiation therapy with 57 patients who had surgical resection plus radiation therapy. Median survival for the surgical resection group was 39.5 weeks, compared with 32 weeks for the biopsy group; the difference was not significant and the comparable survival times for the two groups led to the authors' conclusion that cytoreductive sur-

Table 1 Reports in literature of failure of surgical resection in prolonging survival in patients with malignant glioma

\begin{tabular}{lcc}
\hline Authors & Country & Number of cases \\
\hline Marshall et al, 1974 & US & 29 \\
Coffey et al, 1988 & US & 91 \\
Kala et al, 1993 & Czechoslovakia & 31 \\
Kreth et al, 1993 & Germany & 115 \\
& & Total cases: 266 \\
\hline
\end{tabular}

Table 2 Reports in literature demonstrating benefit of surgical resection in prolonging survival of patients with malignant glioma

\begin{tabular}{lcr}
\hline Authors & Country & Number of cases \\
\hline Salcman, 1985 & (Literature review) & 603 \\
Ammirati et al, 1987 & US & 31 \\
Sandeman et al, 1990 & UK & 359 \\
Vecht et al, 1990 & Netherlands & 243 \\
Forsting et al, 1993 & Germany & 68 \\
Simpson et al, 1993 & US & 645 \\
Jeremic et al, 1994 & Japan, Yugoslavia & 86 \\
Nitta and Sato, 1995 & Japan & 101 \\
& & Total cases: 2136 \\
\hline
\end{tabular}

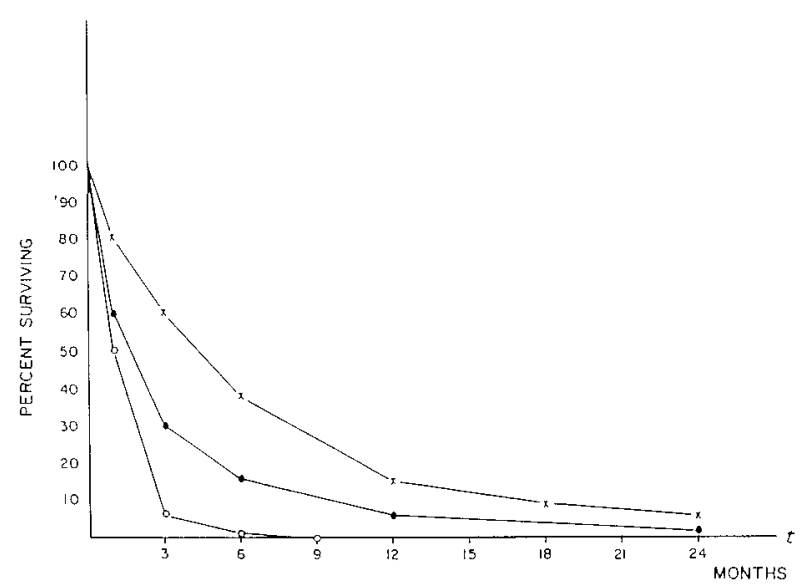

Figure 2 Effect of extent of surgical resection on survival. This graph is based on a review of the literature by Salcman (1985), comprising 603 patients with glioblastoma: extensive surgical resection (X's, 172 cases), partial surgical resection (closed circles, 301 cases), and simple biopsy (open circles, 130 cases). Surgery in these 603 cases was not followed by radiation or chemotherapy (with permission). 
gery is of doubtful value for prolonging life and that radiation therapy is the most effective treatment.

An extensive review of the literature concerning the role of surgery for malignant gliomas by Nazzaro and Neuwelt (1990) concluded that the need for tissue diagnosis and the importance of decompression in symptomatic patients is well-established ... however, the role of cytoreductive surgery, particularly as it relates to survival, remains unclear... aggressive surgical resection when it is the sole therapeutic modality may result in a modest increase in period of survival.' The

A

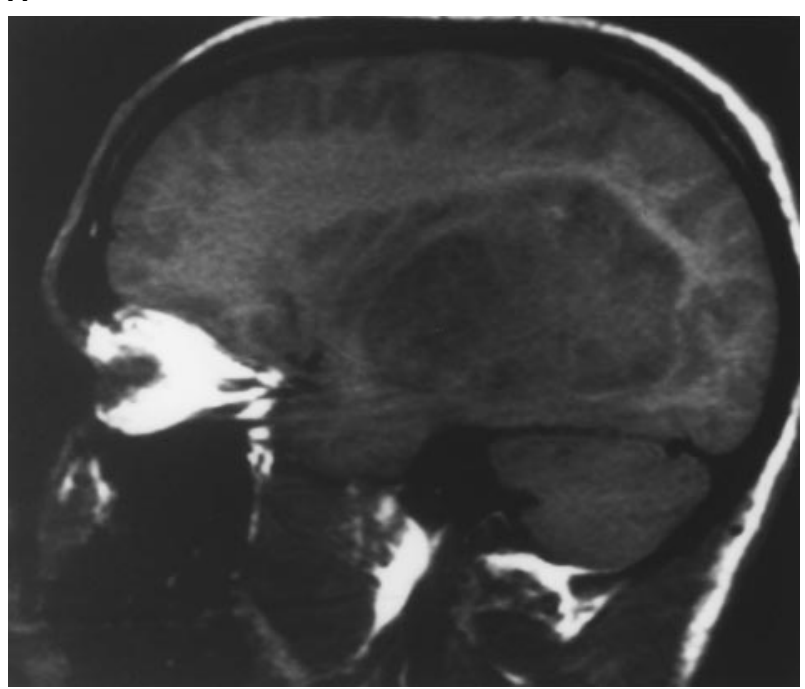

C

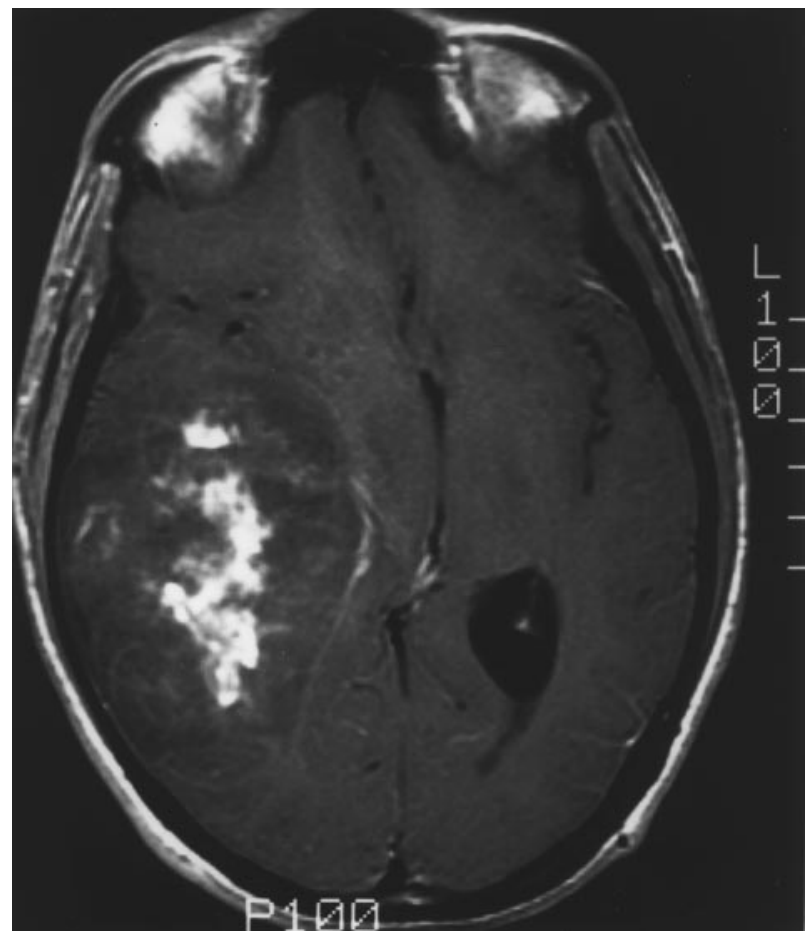

reviewers further suggested that postoperative radiotherapy may well be responsible for the modest extension of survival in patients treated with both surgical resection and radiation.

\section{Extent of surgical resection and survival}

There has been an increasing number of reports, particularly in the past 10 years, specifically addressing the issue of the influence of the extent of surgical resection and outcome. The attention to extent of resection reflects, in part, the greater ability to quantify residual tumor by CT and MRI scanning

B

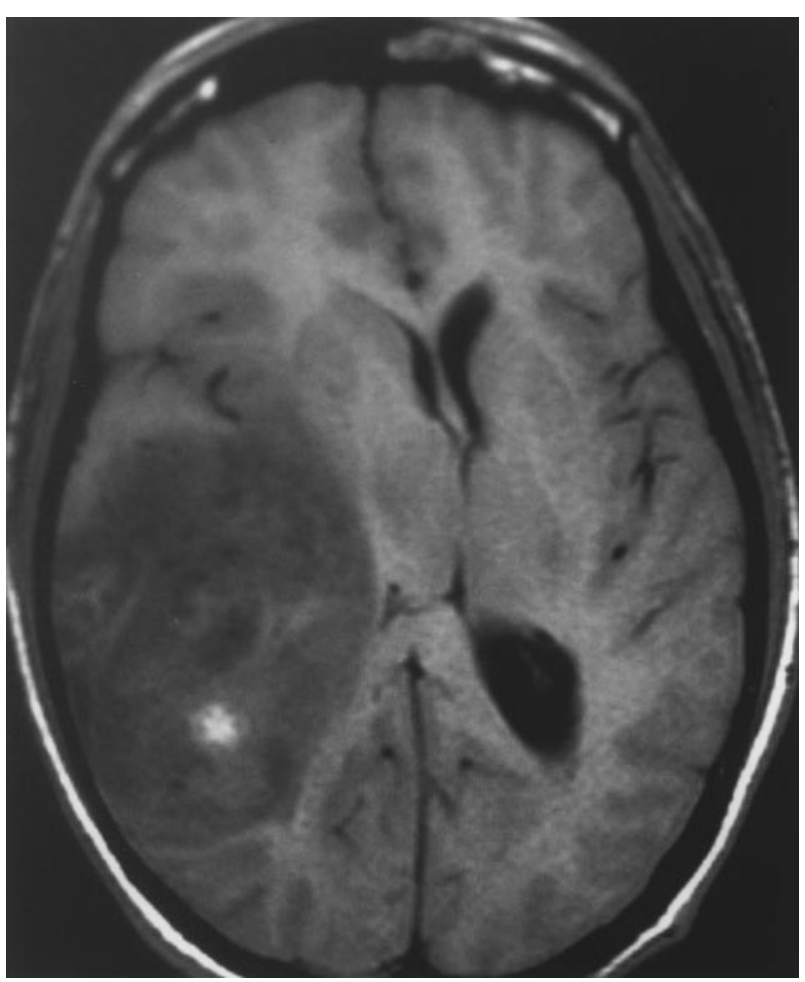

D

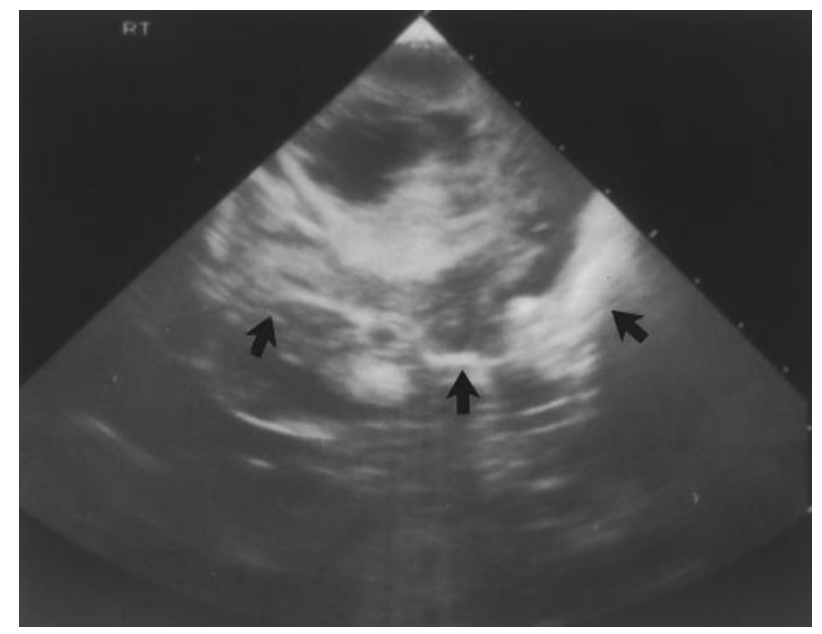


$\mathbf{E}$

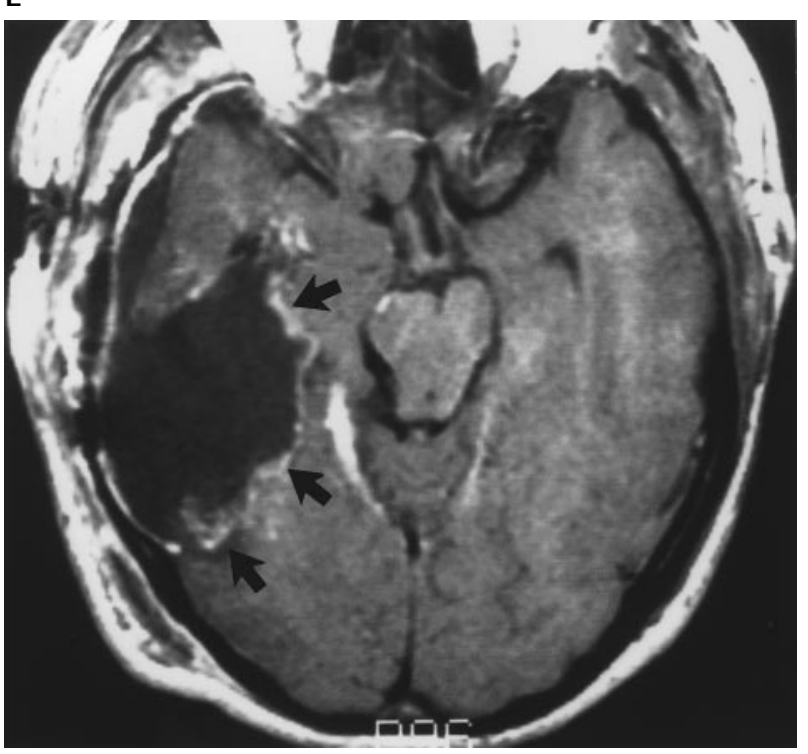

$\mathbf{F}$

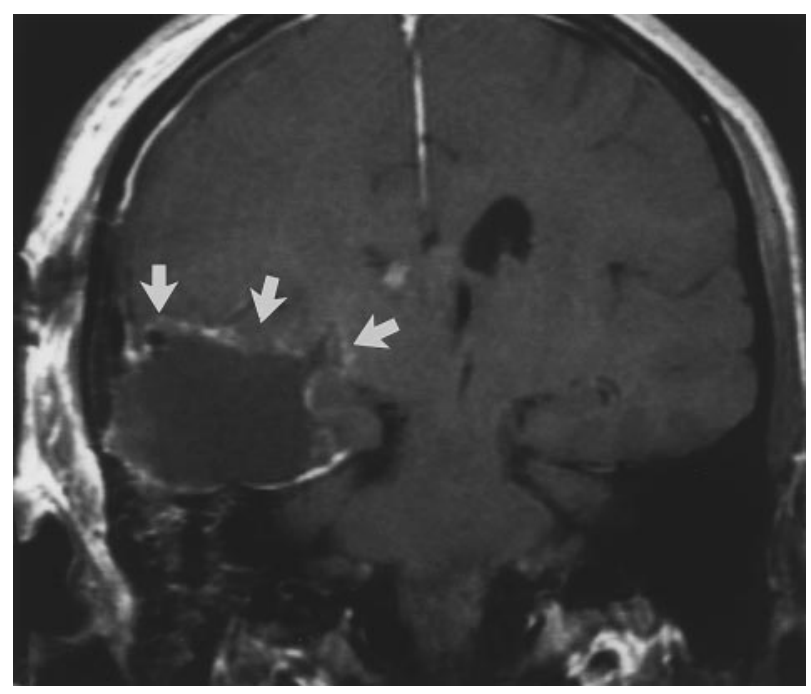

Figure 3 Pre-operative MRI scans (A, B, C of male patient age 36 who presented with a 2-month history of visual disturbance (left hemianopsia), increasing headaches, and, for the few days prior to admission, there was also confusion and nausea. (A) Pre-operative sagittal T-1 weighted scan showing low-intensity large irregular right temporo-parietal mass. (B) Axial T-1 weighted scan showing temporo-parietal mass. (C) Axial T-1 weighted scan with contrast showing irregular enhancement within mass. (D) Intra-operative ultrasound imaging to aid in delineating the deeper portions of the tumor. Arrows indicate deep margin of tumor interface with surrounding normal brain. ( $\mathbf{E}$ and $\mathbf{F}$ ) MRI scans with contrast 1 day after surgery; axial and coronal T-1 weighted images showing irregular rim of high signal consistent with residual blood elements (methemoglobin) in the tumor bed (arrows). There is a small, irregularly shaped subcentimeter enhancing nodule in the medial temporal lobe in the region of the uncus, probably representing a focus of residual tumor. Post-operatively, apart from persistent left homonymous hemianopsia, the patient was neurologically intact. He received a course of regional radiotherapy and returned to work as a draftsman 2 months later. Now 6 months after surgery, and depending upon the appearance of the next MRI scan, consideration will be given to stereotaxic radiotherapy focused on the possible residual tumor nodule in the uncus; chemotherapy will also be considered.

(Forsting et al, 1993). Table 2 lists papers which specifically address the issue of extent of resection; each of these papers points to a positive correlation between radical resection and longer survival. Salcman (1985) pooled the results of studies comprising 603 cases, graphically illustrated in Figure 2. These cases had varying degrees of surgical resection without subsequent radiation or chemotherapy. Survival of 172 cases with extensive surgical resection was 13 and $4 \%$ at 1 and 2 years respectively. Partial resection (301 cases) had a 4 and $2 \%$ survival at 1 and 2 years respectively. Cases of simple biopsy ( 13 cases) had $0 \%$ survival at 1 year. In the study by Vecht et al (1990), overall median survival in all patients (including extensive or partial resection) with anaplastic astrocytoma and glioblastoma, was 8 and 4 months, respectively, with a 2-year survival of 13 and $0.5 \%$, respectively. However, extensive surgery in their series was significantly correlated with a better immediate post-operative performance, a lower 1-year mortality rate and a longer survival, in both anaplastic astrocytoma and glioblastoma.

Simpson et al (1993) found that patients with total resection had a median survival of 11.3 months compared to 6.6 months for biopsy only; there was also a significant difference in median survival for partial resection versus biopsy only (10.4 versus 6.6 months). Tumor size was not a prognostic factor in survival. In the series by Sandeman et al (1990), median survival was 14 months in the surgical resection group, 4 months in the biopsy group, and 2.2 months in the no-craniotomy surgery group; these authors comment, however, that the craniotomy group consisted of patients with better preoperative prognostic indicators than the biopsy group. They point to the need for prospective trials randomizing patients to limited and radical resection groups.

A total of 266 cases listed in Table 1 represent the database for the four papers which report no benefit for surgical resection. Table 2 lists a total of 2136 accumulated cases in the eight papers which favor extensive surgical removal of malignant gliomas. This large collection of patients (Table 2) from multiple centers in the US, Europe and Japan tends to add credibility to the validity of extensive resection.

\section{Reoperation for recurrent glioma}

In the past, reoperation for recurrent glioma has been relatively infrequent, in the range of $0-10 \%$ 
(Salcman, 1996), and has generally been offered to younger patients in stable neurological condition. There is increasing evidence, however, that reoperation can offer reasonable duration of quality survival. Salcman (1996) states that 'the rationale for primary surgery may apply equally well to reoperation ..... Median survival time has been reported as 36-40 weeks from the time of reoperation (Harsh et al, 1987; Rostomily et al, 1994; Salcman, 1996). Longer survival was associated with higher preoperative Karnofsky performance scores, lower grade histology at the time of recurrence, and lobar versus deep tumor location. In the series of Rostomily et al (1994), surgical debulking was associated with longer time to tumor progression but not survival. A common observation in relation to the results of first operation for malignant glioma is that there is a positive correlation between preoperative neurological status and quality and duration of survival. A similar relationship has been reported in the case of reoperation for recurrent glioma (Rostomily et al, 1994; Young et al, 1981). It has been recommended, therefore, that reoperation be offered to patients on the basis of either clinical or radiographic worsening, rather than deferring surgery to the point of neurological deterioration (Salcman, 1990).

\section{Illustrative cases}

Figure 3 illustrates a case of a large anaplastic astrocytoma with nearly total surgical resection. Figure 4 illustrates a case of another patient with a malignant mixed glioma in the dominant hemisphere involving the speech area and for which craniotomy was carried out with the patient awake to enable electrophysiological brain mapping to identify the speech area.

\section{Multimodality therapy}

As discussed previously in this paper, surgery for malignant glioma is intended to establish diagnosis and to provide mechanical cytoreduction to reduce intracranial pressure and possibly alter tumor kinetics. Although tumor cytoreduction appears to be vital, the presence of viable tumor cells beyond the enhancing margin of tumor points to the necessity of surgery as part of a multimodality treatment strategy (Fransen and de Tribolet, 1993; Laws, 1995; Salcman, 1990). Ideally, maximal treatment embracing various modalities is offered 'up front' rather than delaying a particular treatment until tumor recurrence becomes evident. The infiltrative portion of the tumor - beyond the margins of tumor resection - are often invisible to imaging techniques but these viable tumor cells constitute the source of future recurrence and ultimate fatal outcome. It has been reported that two-thirds of all astrocytomas dedifferentiate to a more malignant grade at the time of the first recurrence (Müller et al, 1977).

Therapeutic adjuncts widely used at present include radiotherapy and, to a lesser extent, chemotherapy. Advances in radiotherapy include the use of altered fractionation schedules, stereotaxic brachytherapy and stereotaxic radiosurgery. Boron neutron capture therapy remains investigational.
A

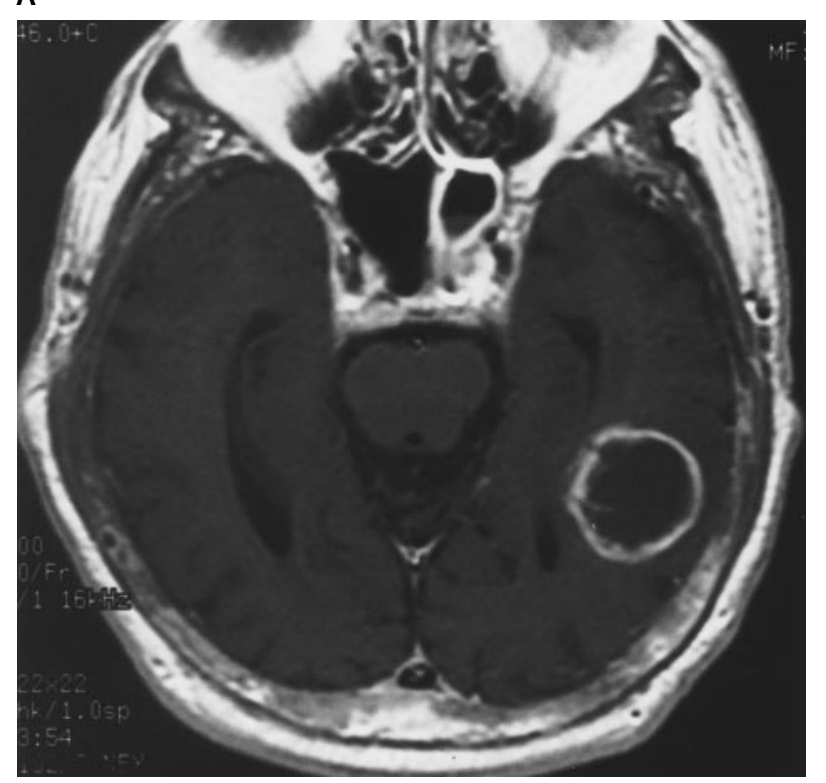

B

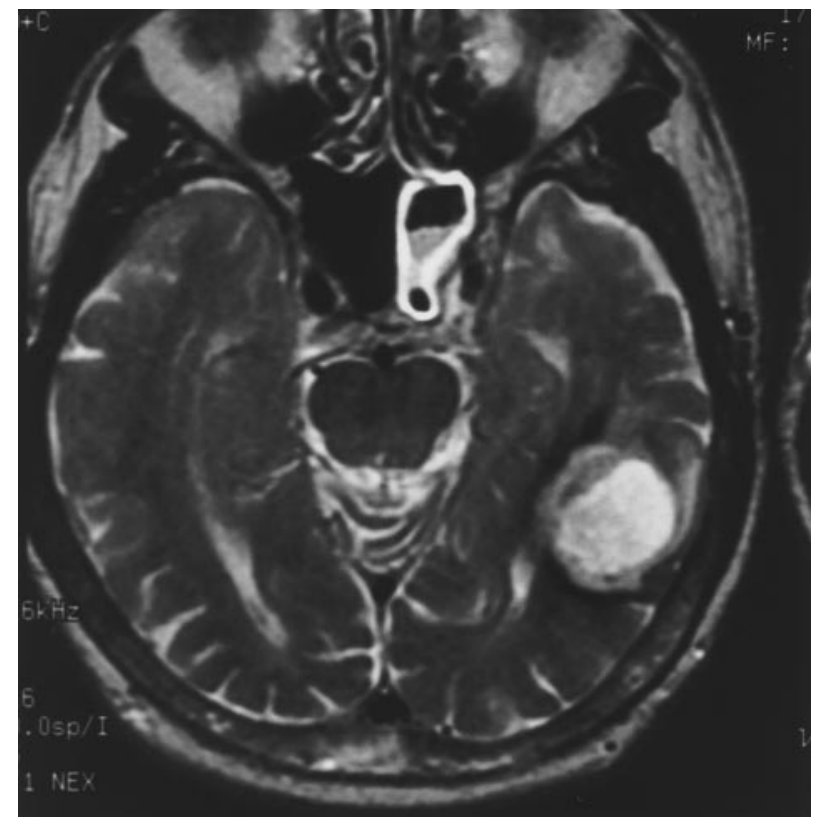


The value of chemotherapy has been limited by the blood brain barrier (BBB) and by systemic as well as neuro-toxicity. There has been some interest in the potential for direct delivery of chemotherapeutic agents to the tumor by superselective intraarterial injection via microcatheters placed in small blood vessels feeding the tumor (Larner et al, 1995). The most promising new development in the application of chemotherapy for brain tumor has been the introduction of biodegradable polymers impregnated with che-

\section{C}

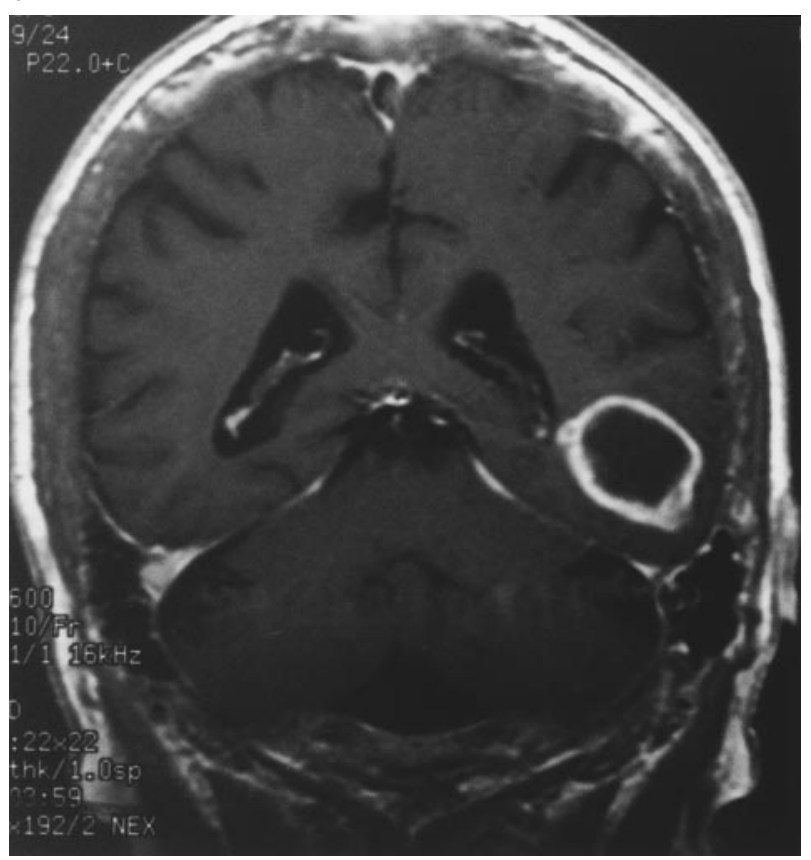

$\mathbf{E}$

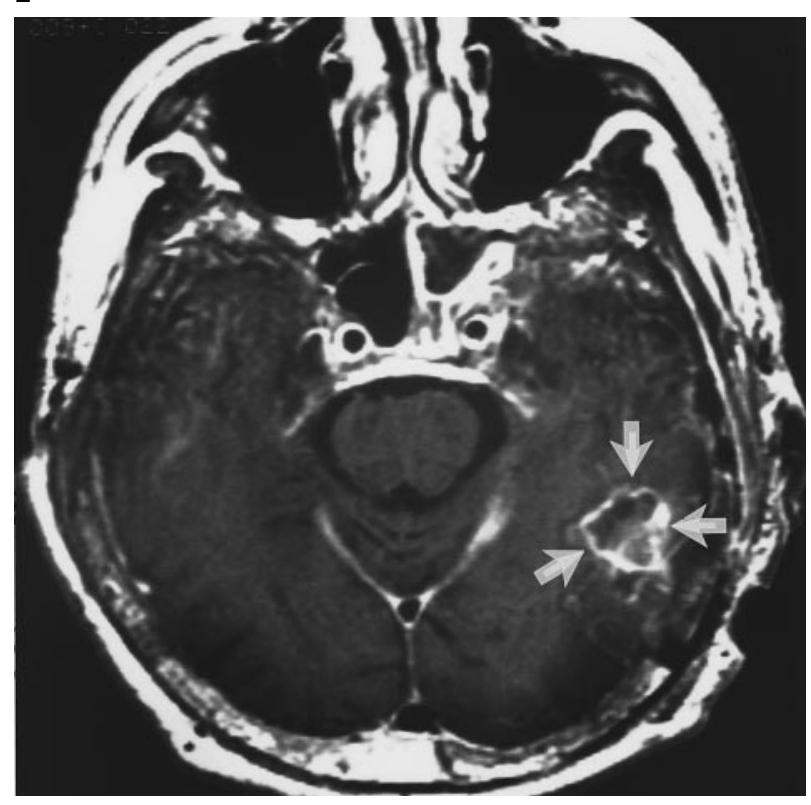

motherapeutic agents (Brem et al, 1995; Valtonen et al, 1997). These polymers, in the form of dimesize wafers applied topically in the tumor bed at the time of surgical resection, slowly release the chemotherapeutic agent (carmustine [BCNU]) as they degrade over a period of weeks. Although carmustine is the agent currently used in the polymer-impregnated wafers, other agents, particularly camptothecin (Brem, 1997) are being tested experimentally and may be more effective than carmustine. The advantage of topical applica-
D

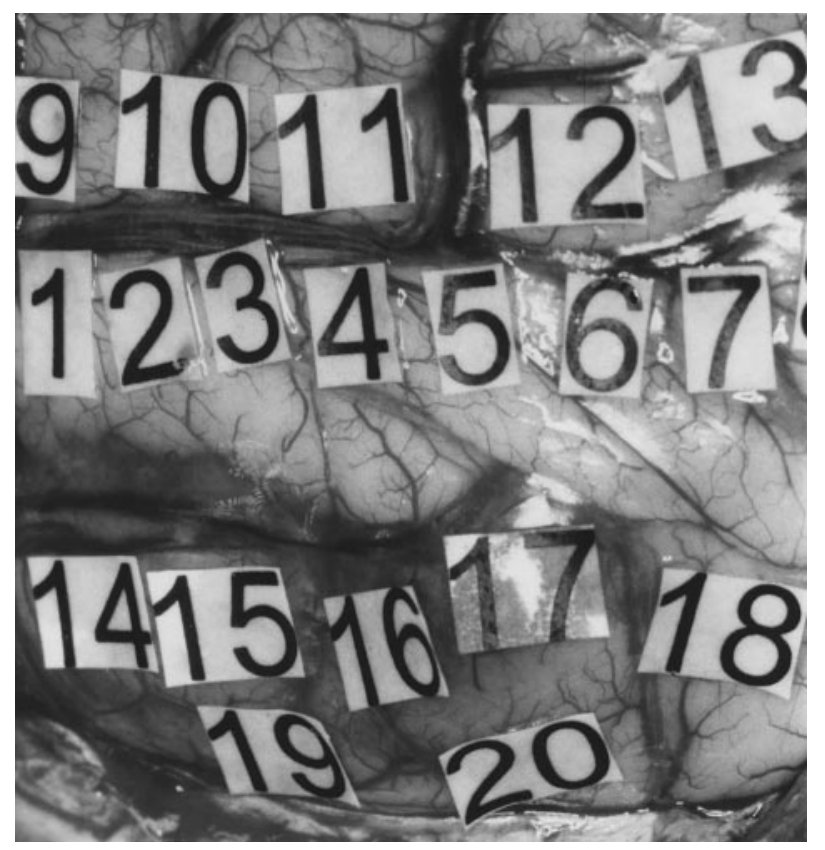

Figure 4 Pre-operative MRI scans (A, B, C) of male patient aged 72 with 1-month history of sudden onset of difficulty with word finding, reading and comprehension. (A) Axial T-1 weighted scan with contrast, showing circumscribed mass with high intensity rim in posterior left temporal lobe. (B) Axial T-2 weighted image showing mass with central region of high signal. (C) Coronal T-1 weighted image with contrast, showing circumscribed mass above tentorium and adjacent to left lateral ventricle. (D) Craniotomy was carried out with patient awake to permit electrophysiological brain mapping to identify speech area because lesion was in region of Wernicke's area. Search was also made for the motor cortex. Paper number tags were applied to the cortical surface to serve as markers for stimulation sites. A portion of the tumor was located in an area where electrical stimulation produced speech arrest so that this restricted the effort to achieve a radical resection of the tumor. (E) Axial MRI scan with contrast 1 day after surgery, showing blood in tumor bed and ring enhancement (arrows) suggestive of residual tumor. It was estimated that there was less than $10 \%$ residual tumor. Post-operatively, speech was slightly worse for several days, then returned to pre-operative baseline and was considerably improved 1 month later. The patient was given a course of 3-D regional radiation therapy and a boost of stereotaxic radiosurgery directed to the residual tumor. Now 6 months after surgery, the patient is self-sufficient although he has not returned to work as a part-time bus driver. He still has difficulty with reading and there is some delay in word-finding; he remains otherwise neurologically intact. 
tion in the tumor bed is the by-passing of the BBB and the virtual elimination of systemic toxicity. Further potential for the use of polymers for delivery of agents directly to the tumor include impregnation with radiosensitizers, anti-angiogenesis agents and cytokines (Brem, 1997).

Monoclonal antibodies specific for glioma cells are currently in limited use as an adjunct in tumor management (Miyamoto et al, 1996). The antibodies, injected intravenously, are used as carriers for isotopes, although, theoretically, the antibodies could be bound to other agents such as immunotoxins. Future innovative treatments are likely to emerge from ongoing studies in molecular biology. Among these is immunotherapy relating to the cellular immune response in patients with malignant glioma (Tada and de Tribolet, 1997). Another is the application of gene therapy to human brain tumor. Trials in humans have entailed the stereotaxic injection of viral vectors directly into brain tumors to

\section{References}

Ammirati M, Vick N, Liao YL, Ciric I, Mikhael M (1987). Effect of the extent of surgical resection on survival and quality of life in patients with supratentorial glioblastomas and anaplastic astrocytomas. Neurosurgery 21: 201-206.

Beaney RP, Brooks DJ, Leenders KL, Thomas DG, Jones $\mathrm{T}$, Halnan KE (1985). Blood flow and oxygen utilisation in the contralateral cerebral cortex of patients with untreated intracranial tumours as studied by positron emission tomography, with observations on the effect of decompressive surgery. I Neurol Neurosurg Psychiatr 48: 310-319.

Brem H (1997). Personal Communication.

Brem H, Piantadosi S, Burger PC, Walker M, Selker R, Vick NA, Black K, Sisti M, Brem S, Mohr G, Muller P, Morawetz R, Schold SC, and The Polymer-Brain Tumor Study Group (1995). Placebo-controlled trial of safety and efficacy of intraoperative controlled delivery by biodegradable polymers of chemotherapy for recurrent gliomas. Lancet 345: 1008-1012.

Burger PC (1987). The anatomy of astrocytomas. Mayo Clin Proc 62: 527-529.

Chang CH, Horton J, Schoenfeld D, Salazer O, PerezTamayo R, Kramer S, Weinstein A, Nelson JS, Tsukada Y (1983). Comparison of postoperative radiotherapy and combined postoperative radiotherapy and chemotherapy in the multidisciplinary management of malignant gliomas. A joint Radiation Therapy Oncology Group and Eastern Cooperative Oncology Group study. Cancer 52: 999-1007.

Choksey MS, Valentine A, Shawdon H, Freer CE, Lindsay KW (1989). Computed tomography in the diagnosis of malignant brain tumours: do all patients require biopsy? I Neurol Neurosurg \& Psychiatr 52: $821-825$.

Ciric I, Ammirati M, Vick N, Mikhael M (1987). Supratentorial gliomas: Surgical considerations and immediate postoperative results. Gross total resection versus partial resection. Neurosurgery 21: 21-26. transfect the cells to synthesize genes leading to tumor cell destruction (Ram and Oldfield, 1977).

Basic research and clinical experience with gliomas are yielding greater understanding of the biology of these complex, heterogeneous malignancies. The evidence suggests that therapeutic potential may be enhanced by aggressive multimodality therapy. This entails the combination of radical surgical reduction of tumor burden with adjunctive treatments to suppress or eradicate the infiltrative component of the neoplasm.

\section{Acknowledgements}

My thanks to Amy R Black, MA, Daniel O Black, MD, Tricia Gray, MBA, Charles Levy, BA, Mary McCabe, MA, Emily Morton and Lynn Reynolds for their invaluable assistance in the preparation of the manuscript.

Coffey RJ, Lunsford LD, Taylor FH (1988). Survival after stereotactic biopsy of malignant gliomas. Neurosurgery 22: $465-473$.

Darling JL, Lewandowicz GM, Thomas DGT (1997). Chemosensitivity testing of human malignant brain tumors. In: Advances in Neuro-Oncology II. Kornblith PL and Walker MD (eds). Futura Publishing Co. Armonk, New York, pp 413-434.

Dyck P, Bouzaglou A, Solti-Bohman LG, Gruskin P (1983). Computer-aided, CT-guided biopsy and brachytherapy of brain tumors. Bull Clin Neurosci 48: $122-138$

Fadul C, Wood J, Thaler H, Galicich J, Patterson Jr RH, Posner JB (1988). Morbidity and mortality of craniotomy for excision of supratentorial gliomas. Neurology 38: $1374-1379$.

Forsting M, Albert FK, Kunze S, Adams HP, Zenner D, Sartor K (1993). Extirpation of glioblastomas: MR and CT follow-up of residual tumor and regrowth patterns. AJNR 14: $77-87$.

Fransen P, de Tribolet N (1993). Surgery of supratentorial tumors. Current Opinion in Oncology 5: 450-457.

Green SB, Byar DP, Walker MD, Pistenmaa DA, Alexander Jr E, Batzdorf U, Brooks WH, Hunt WE, Mealey Jr J, Odom GL, Paoletti P, Ransohoff J 2nd, Robertson JT, Selker RG, Shapiro WR, Smith Jr KR, Wilson CB, Strike TA (1983). Comparisons of carmustine, procarbazine and high-dose methylprednisolone as additions to surgery and radiotherapy for the treatment of malignant glioma. Cancer Treat Rep 67: $121-132$.

Gutin PH, Leibel SA (1985). Stereotaxic interstitial irradiation of malignant brain tumors. Neurol Clin 3: $883-893$

Halperin EC, Burger PC, Bullard DE (1988). The fallacy of the localized supratentorial malignant glioma. Int $J$ Radiation Oncol Biol Phys 15: 505-509. 
Harsh GR IV, Levin VA, Gutin PH, Seager M, Silver P, Wilson CB (1987). Reoperation for recurrent glioblastoma and anaplastic astrocytoma. Neurosurgery 21: $615-621$

Hochberg FH, Pruitt A (1980). Assumptions in the radiotherapy of glioblastoma. Neurology 30: $907-911$.

Hollerhage HG, Zumkeller M, Becker M, Dietz H (1991). Influence of type and extent of surgery on early results and survival time in glioblastoma multiforme. Acta Neurochir (Wien) 113: 31-37.

Hoshino $\mathrm{T}$ (1984). A commentary on the biology and growth kinetics of low-grade and high-grade gliomas. $J$ Neurosurg 61: 895-900.

Jelsma R, Bucy PC (1967). The treatment of glioblastoma multiforme of the brain. J Neurosurg 27: 388-400.

Jeremic B, Grujicic D, Antunovic V, Djuric L, Stojanovic M, Shibamoto Y (1994). Influence of extent of surgery and tumor location on treatment outcome of patients with glioblastoma multiforme treated with combined modality approach. J Neuro-Oncol 21: 177-185.

Kala M, Sramek V, Houdek M, Vaverka M, Zmrzlik P (1993). Treatment of glioblastoma multiforme (Czech). Casopis Lekaru Ceskych 132: 653-656.

Kelly PJ, Daumas-Duport C, Scheithauer BW, Kall BA, Kispert DB (1987). Stereotactic histologic correlations of computed tomography- and magnetic resonance imaging-defined abnormalities in patients with glial neoplasms. Mayo Clin Proc 62: 450-459.

Kreth FW, Warnke PC, Scheremet R, Ostertag CB (1993). Surgical resection and radiation therapy versus biopsy and radiation therapy in the treatment of glioblastoma multiforme. J Neurosurg 78: 762-766.

Kristiansen K, Hagen S, Kollevold T, Torvik A, Holme I, Nesbakken R, Hatlevoll R, Lindgren M, Brun A, Lindgren S, Notter G, Andersen AP, Elgen K (1981). Combined modality therapy of operated astrocytomas grade III and IV. Confirmation of the value of postoperative irradiation and lack of potentiation of bleomycin on survival time: a prospective multicenter trial of the Scandinavian Glioblastoma Study Group. Cancer 47: 649-652.

Larner JM, Phillips CD, Dion JE, Jensen ME, Newman SA, Jane JA (1995). A phase 1-2 trial of superselective carboplatin, low-dose infusional 5-fluorouracil and concurrent radiation for high-grade gliomas. Am J Clin Oncol 18: $1-7$.

Laws Jr ER (1995). Radical resection for the treatment of glioma. Clin Neurosurg 42: 480-487.

Marshall LF, Jennett B, Langfitt TW (1974). Needle biopsy for the diagnosis of malignant glioma. JAMA 228: $1417-1418$.

Miyamoto CT, Brady LW, Rackover MA, Emrich J, Class R, Bender H, Micaily B, Steplewski Z (1996). The use of epidermal growth factor receptor- 425 monoclonal antibodies radiolabeled with Iodine-125 in the adjuvant treatment of patients with high grade gliomas of the brain. In: Systemic Radiotherapy with Monoclonal Antibodies. Options and Problems. Sautter-Bihl M-L, Bihl H, Wannenmacher M (eds). Springer-Verlag, Berlin, Heidelberg pp 183-192.

Müller W, Áfra D, Schröder R (1977). Supratentorial recurrences of gliomas. Morphological studies in relation to time intervals with astrocytomas. Acta Neurochir (Wien) 37: 75-91.
Nazzaro JM, Neuwelt EA (1990). The role of surgery in the management of supratentorial intermediate and high-grade astrocytomas in adults. $J$ Neurosurg 73: $331-344$

Nitta T, Sato K (1995). Prognostic implications of the extent of surgical resection in patients with intracranial malignant gliomas. Cancer 75: 2727-2731.

Rajan B, Pickuth D, Ashley S, Traish D, Monro P, Elyan S, Brada M (1994). The management of histologically unverified presumed cerebral gliomas with radiotherapy. Int J Radiation Oncol Biol Phys 28: 405-413.

Ram Z, Oldfield EH (1997). Genetic approaches for the therapy of malignant brain tumors. In: Advances in Neuro-Oncology II. Kornblith PL, Walker MD (eds). Futura Publishing Co. Armonk, New York. pp 541551.

Rostomily RC, Spence AM, Duong D, McCormick K, Bland M, Berger MS (1994). Multimodality management of recurrent adult malignant gliomas: results of a phase II multiagent chemotherapy study and analysis of cytoreductive surgery. Neurosurgery 35: 378-388.

Salcman M, Kaplan RS, Samaras GM, Ducker TB, Broadwell D (1982). Aggressive multimodality therapy based on a multicompartmental model of glioblastoma. Surgery 92: 250-259.

Salcman M (1985). Supratentorial gliomas: Clinical features and surgical therapy. In: Neurosurgery. Wilkins RJ, Rengarchary SS (eds). McGraw-Hill Book Co., New York, vol 1, pp 579-590.

Salcman M (1990). Malignant glioma management. Neurosurg Clin N Amer 1: 49-63.

Salcman M (1996). Supratentorial gliomas: Clinical features and surgical therapy. In: Neurosurgery Wilkins RJ and Rengachary SS (eds). Second Edition, McGraw-Hill Book Co., New York. vol 1, pp 777-788.

Sandeman DR, Sandeman AP, Buxton P, Hughes HH, Chadwick DW, Williams IR, Baker RD, Foy PM, Shaw DM (1990). The management of patients with an intrinsic supratentorial brain tumour. Br J Neurosurg 4: $299-312$.

Shapiro WR (1982). Treatment of neuroectodermal brain tumors. Ann Neurol 12: 231-237.

Simpson JR, Horton J, Scott C, Curran WJ, Rubin P, Fischbach J, Isaacson S, Rotman M, Asbell SO, Nelson JS, Weinstein AS, Nelson DF (1993). Influence of location and extent of surgical resection on survival of patients with glioblastoma multiforme: results of three consecutive Radiation Therapy Oncology Group (RTOG) clinical trials. Int J Radiation Oncology Biol Phys 26: $239-244$.

Tada M, de Tribolet $N$ (1997). Immunobiology of malignant gliomas. In: Advances in Neuro-Oncology II. Kornblith PL, Walker MD (eds). Futura Publishing Co., Armonk, New York, pp 447-467.

Valtonen S, Timonen U, Toivanen P, Kalimo $\mathrm{H}$, Kivipelto L, Heiskanen O, Unsgaard G, Kuurne T (1997). Interstitial chemotherapy with carmustineloaded polymers for high-grade gliomas: a randomized double-blind study. Neurosurgery 41: 44-48.

Vecht CJ, Avezaat CJ, van Putten WL, Eijkenboom WM, Stefanko SZ (1990). The influence of the extent of surgery on the neurological function and survival in malignant glioma. A retrospective analysis in 243 patients. J Neurol Neurosurg Psychiatr 53: 466-471. 
Walker MD, Alexander Jr E, Hunt WE, MacCarty CS, Mahaley Jr MS, Mealey Jr J, Norrell HA, Owens G, Ransohoff J, Wilson CB, Gehan EA, Strike TA (1978). Evaluation of BCNU and/or radiotherapy in the treatment of anaplastic gliomas. A cooperative clinical trial. J Neurosurg 49: $333-343$.

Walker MD, Green SB, Byar DP, Alexander Jr E, Batzdorf U, Brooks WH, Hunt WE, MacCarty CS, Mahaley Jr MS, Mealey Jr J, Owens G, Ransohoff J 2nd, Robertson JT, Shapiro WR, Smith Jr KR, Wilson CB, Strike TA (1980). Randomized comparisons of radiotherapy and nitrosoureas for the treatment of malignant glioma after surgery. New Engl J Med 303: 1323-1329.
Young B, Oldfield EH, Markesbery WR, Haack D, Tibbs PA, McCombs P, Chin HW, Maruyama Y, Meacham WF (1981). Reoperation for glioblastoma. J Neurosurg 55: $917-921$. 